\title{
Innervation Patterns of the Pronator Teres Muscle and Their Possible Role in Neurotization: A Systematic Review of Cadaveric Studies
}

\author{
Bhagath Kumar Potu ${ }^{1, *}$, M. V. Ravishankar ${ }^{2}$
}

\begin{abstract}
Background: Contrary to the classic anatomical description, many recent studies have reported wide variations in branching patterns and location of motor branches that are supplying the pronator teres muscle. To understand these variations and their implications in surgical procedures of the nerve transfers, a systematic review was performed on the innervation of pronator teres muscle from cadaveric studies. Methods: A systematic literature search was performed in databases such as Medline, PubMed, Google Scholar, SciELO, ScienceDirect, Cochrane reviews and orthopedics textbooks using the search terms "pronator teres nerve branches"; AND "number" OR "location" OR "length" OR "diameter" yielded 545 article links. Articles were evaluated according to PRISMA guidelines.

Results: A total of twenty cadaveric studies including 648 branches have registered $52.9 \%$ of two branch innervation pattern followed by $31.3 \%$-single branch pattern; $13.5 \%$-three branch pattern; $1.7 \%$-four branch pattern, and $0.4 \%$-five branch patterns, respectively. Of the 403 branches studied for their location in relation with the humeral intercondylar line, most branches were located distal to the line (50.3\%), followed by $32.7 \%$ (proximal to it) and $16.8 \%$ at the line, respectively. The distance of branches located proximal and distal to humeral intercondylar line was in the range of $1.25-10 \mathrm{~cm}$, and $1.1-7.5 \mathrm{~cm}$, respectively. The mean length and diameter of nerves reported were $4.37 \pm 2.43 \mathrm{~cm}$, and $1.5 \mathrm{~mm}$, respectively.

Conclusions: Our data defined the morphometrics of nerve branches and they often met the required diameter for neurotization procedures. Our findings also demonstrated that the morphometrics, branching pattern and their location vary between populations and this information is very vital for surgeons during the nerve transfers.

\section{KEYWORDS}

pronator teres; innervation; morphometrics; neurotization

AUTHOR AFFILIATIONS

${ }^{1}$ Department of Anatomy, College of Medicine and Medical Sciences, Arabian Gulf University, Kingdom of Bahrain

2 Department of Anatomy, JSS Medical College, JSS Academy of Higher Education and Research, Mysuru, Karnataka, India

* Corresponding author: Department of Anatomy, College of Medicine and Medical Sciences, Arabian Gulf University, Kingdom of Bahrain; potubk@agu.edu.bh
\end{abstract}

Received: 14 November 2020

Accepted: 14 April 2021

Published online: 30 July 2021

Acta Medica (Hradec Králové) 2021; 64(2): 77-84

https://doi.org/10.14712/18059694.2021.14

(c) 2021 The Authors. This is an open-access article distributed under the terms of the Creative Commons Attribution License (http://creativecommons.org/licenses/by/4.0), which permits unrestricted use, distribution, and reproduction in any medium, provided the original author and source are credited. 


\section{INTRODUCTION}

Median nerve $(\mathrm{Mn})$ is one of the important branches arising from C5-T1 roots via medial and lateral cords of the brachial plexus. After its formation, Mn descends through the arm along with brachial artery to reach the cubital fossa. Here it is closely related to the pronator teres muscle (PTM). PTM is a fusiform muscle that has a humeral head and an ulnar head. Humeral head extends from the medial epicondyle of humerus and medial intermuscular septum, and an ulnar head that originates from the coronoid process of the ulna. Both heads run downwards and merge to form a common flexor tendon, which inserts at the midportion of the lateral surface of radius $(1,2)$. The usual anatomical description is that the median nerve passes between two-headed PTM and gives a branch to it before entering the forearm (Fig. 1a and $1 \mathrm{~b}$ ). This branching site could be at a variable distance proximal to the elbow joint (3). Contrary to the classic description, many recent studies have reported variability in the motor branches of $\mathrm{Mn}$ that are supplying PTM. And these branches are located at a variable distance either proximal or distal to the humeral intercondylar line (HIL) or at the level of HIL (4-9). In cases, where more than one branch to the PTM is present, these remain as an effective alternative surgical option for nerve transfer procedures $(5,8,10,11)$. To this, a recent experimental study treating lower brachial plexus injury in rats confirmed that the PTM branches seem to be a better donor than the other nerves in their electrophysiological and histological examination (12).

Although a lot of clinical information is available on their role in nerve transfer procedures, the basic anatomical details facilitating the identification of these nerve branches is not so comprehensively reported in the literature. Despite their clinical importance, there is no accurate data available on the number, location and morphometrics of the nerves in association with ethnicity, gender and side. Therefore, we critically reviewed the available

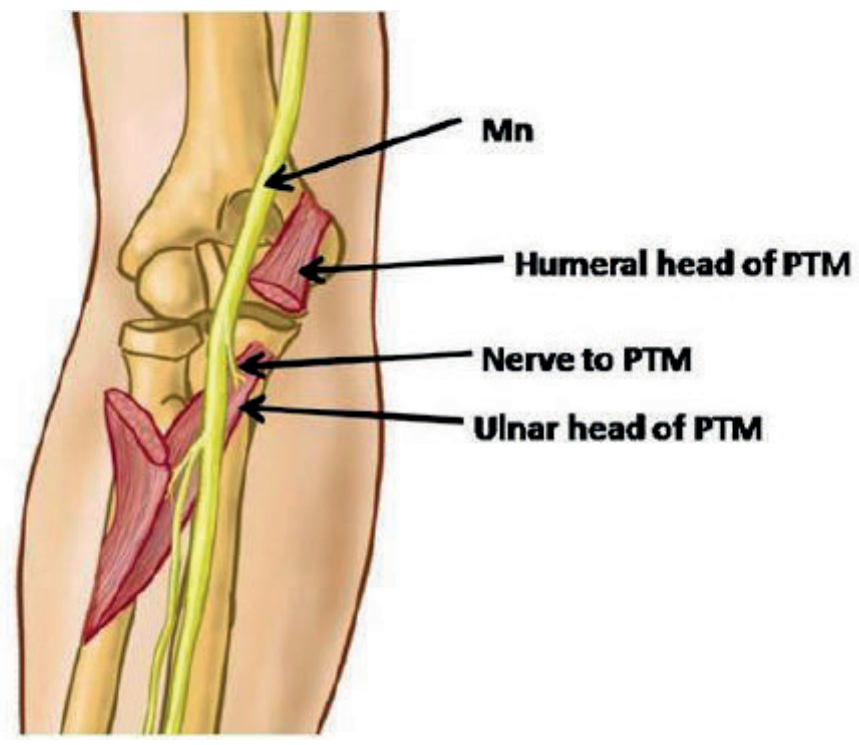

Fig. 1a Schematic diagram showing the pronator teres muscle with its innervation.

Mn: median nerve; PTM: pronator teres muscle. literature regarding the innervation patterns of PTM and quantitatively interpreted the pooled data. We hope that this quantitative data may give a broader perspective to surgeons in avoiding iatrogenic injuries to these nerve branches and harvesting them safely for neurotization procedures.

\section{MATERIALS AND METHODS}

\section{SEARCH STRATEGY AND INCLUSION-EXCLUSION CRITERIA}

A thorough search was made mainly using the electronic databases such as Medline, PubMed, Google Scholar, SciELO, ScienceDirect, Cochrane reviews and orthopedics textbooks. The keywords for search used were as follows; [("pronator teres nerve branches") AND "number OR location OR length OR diameter")]. To arrive at a standard dataset, we have strictly confined our search criteria to the cadaveric studies by excluding all the case reports, case series, letter to editor and brief communications from other clinical sources. The mean pooled data on PTM branches,

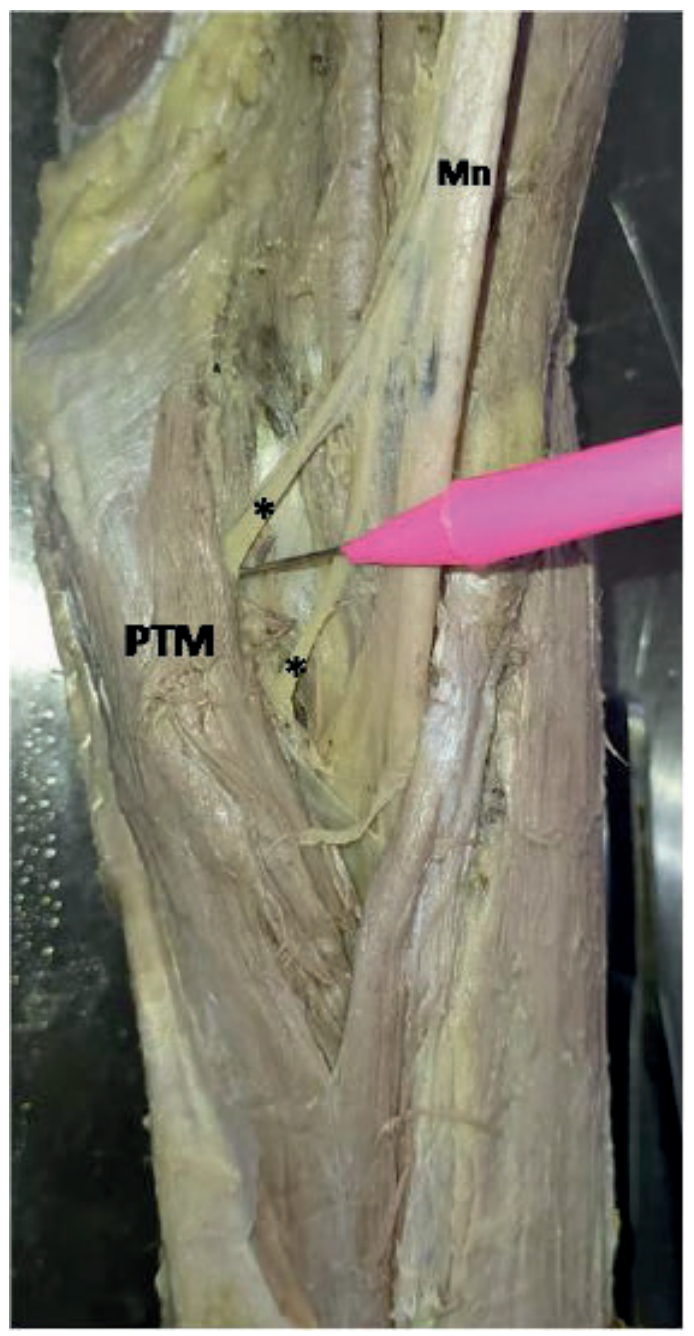

Fig. Ib A cadaveric dissection showing the pronator teres muscle with its innervation (two branch pattern).

* Showing the PTM branches. Mn: median nerve; PTM: pronator teres muscle. 


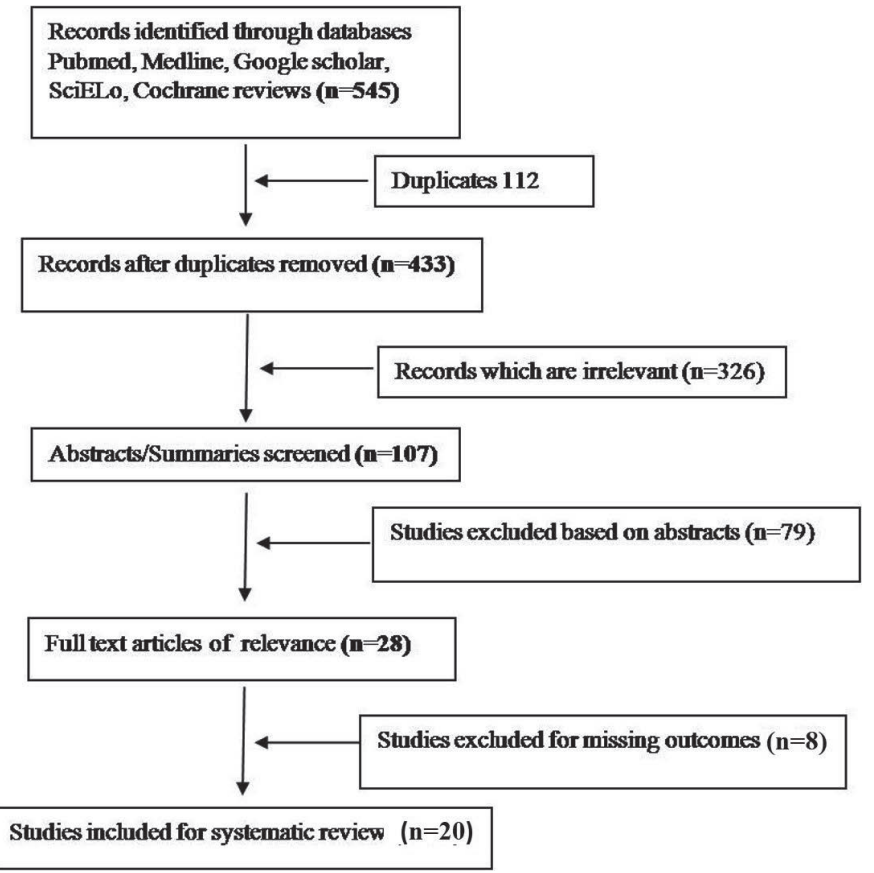

Fig. 2 Showing the application of selection criteria as per PRISMA guidelines.

their location with regards to HIL and their side and gender-based values were set to be the outcomes of our study. The references of the included articles were checked, and duplicates were deleted. We have not set restrictions on date or language of the studies. Initial screening on titles and abstracts of the articles were done to obtain the fulltext articles (Fig. 2). The data collection was done using the guidelines of Preferred Reporting Items for Systematic reviews and MetaAnalyses (PRISMA) checklist (13). Search strategy was carried out independently by two authors and no conflict was noticed.

\section{STATISTICAL ANALYSIS}

Extracted data included the country of study, sample size, number of the PTM branches and their length, the diameter and location. The mean \pm SD were calculated for all the outcomes independently by two observers and no conflict was noticed. Then the mean values of all the outcomes were analyzed as per the population using SPSS Version 23.0 (USA).

\section{RESULTS}

A total of twenty cadaveric studies met the inclusion criteria (Fig. 2). All the limbs are of adults with an age ranging from $20-89$ years. Five studies $(4,8,10,17,22)$ reported their gender distribution with 69 males and 56 females from the total sample. Six studies $(7,17,21,23,25,26)$ have reported data on 159 left and 154 right limbs. Tables 1 and 2 show the characteristics of limbs with PTM and their branches.

Tab. 1 Characteristics of the included studies.

\begin{tabular}{|c|c|c|c|c|c|c|c|c|}
\hline Studies (year) & Region & $\begin{array}{c}\text { Sample size } \\
\text { of limbs }\end{array}$ & Type of study & Age (Years) & Male & Female & Left & Right \\
\hline Sunderland, 1978 [14] & UK & 20 & Cadaveric & NR & NR & NR & NR & NR \\
\hline Fuss and Wurzl, 1990 [15] & Austria & 50 & Cadaveric & NR & NR & NR & NR & NR \\
\hline Gunther et al., 1992 [16] & USA & 20 & Cadaveric & NR & NR & NR & NR & NR \\
\hline Canovas et al., 1998 [4] & France & 10 & Cadaveric & $70-85$ & 4 & 6 & NR & NR \\
\hline Chantelot et al., 1999 [17] & France & 50 & Cadaveric & NR & 20 & 30 & 25 & 25 \\
\hline Tung and Mackinnon, 2001 [5] & USA & 31 & Cadaveric & NR & NR & NR & NR & NR \\
\hline Alves et al., $2004[18]$ & Brazil & 18 & Cadaveric & NR & NR & NR & NR & NR \\
\hline Safwat and Abdel-Meguid, 2007 [6] & Saudi Arabia & 23 & Cadaveric & NR & NR & NR & NR & NR \\
\hline Demirci et al., 2007 [19] & Turkey & 34 & Cadaveric & NR & NR & NR & NR & NR \\
\hline Tubbs et al., $2011[10]$ & USA & 20 & Cadaveric & $60-89$ & 12 & 8 & NR & NR \\
\hline Pushpalatha et al., 2011 [20] & India & 50 & Cadaveric & NR & NR & NR & NR & NR \\
\hline Bindurani et al., 2013 [21] & India & 50 & Cadaveric & $20-50$ & NR & NR & 26 & 24 \\
\hline Yang et al., 2014 [22] & China & 30 & Cadaveric & NR & 18 & 12 & NR & NR \\
\hline Gupta et al., 2015 [23] & India & 24 & Cadaveric & NR & NR & NR & 12 & 12 \\
\hline Olewnik et al., 2017 [7] & Poland & 50 & Cadaveric & NR & NR & NR & 26 & 24 \\
\hline Basanagouda and Halagatti, 2017 [24] & India & 62 & Cadaveric & NR & NR & NR & NR & NR \\
\hline Caetano et al., 2018 [8] & Brazil & 30 & Cadaveric & NR & 15 & NR & NR & NR \\
\hline Gaikwad et al., 2018 [25] & India & 39 & Cadaveric & NR & NR & NR & 20 & 19 \\
\hline Bertelli et al., 2020 [9] & Brazil & 32 & Cadaveric & NR & NR & NR & NR & NR \\
\hline Vantmuri and Joshi, $2020[26]$ & India & 100 & Cadaveric & $25-70$ & NR & NR & 50 & 50 \\
\hline
\end{tabular}

NR: not reported. 
Tab. 2 Outcomes of different studies on the number of branches to PTM.

\begin{tabular}{|c|c|c|c|c|c|c|}
\hline \multirow{2}{*}{$\begin{array}{c}\text { Studies (year) } \\
\& \\
\text { Region }\end{array}$} & \multirow{2}{*}{$\begin{array}{l}\text { Gender/ } \\
\text { side }\end{array}$} & \multicolumn{5}{|c|}{ Number of PTM branches } \\
\hline & & One & Two & Three & Four & Five \\
\hline Sunderland (1978) - UK [14] & Overall & 7 & 14 & 0 & 0 & 0 \\
\hline Fuss and Wurzl (1990) - Austria [15] & Overall & 14 & 22 & 10 & 4 & 0 \\
\hline Gunther et al. (1992) - USA [16] & Overall & 1 & 6 & 3 & 0 & 0 \\
\hline Canovas et al. (1998) - France [4] & Overall & 0 & 10 & 0 & 0 & 0 \\
\hline Chantelot et al. (1999) - France [17] & Overall & 28 & 13 & 1 & 0 & 0 \\
\hline Tung and Mackinnon (2001) - USA [5] & Overall & 8 & 16 & 5 & 1 & 0 \\
\hline Alves et al. (2004) - Brazil [18] & Overall & NS & NS & NS & NS & NS \\
\hline Demirci et al. (2007) - Turkey [19] & Overall & 4 & 19 & 10 & 1 & 0 \\
\hline Safwat and Abdel-Meguid (2007) - Saudi Arabia [6] & Overall & 0 & 23 & 0 & 0 & 0 \\
\hline Tubbs et al. (2011) - USA [10] & Overall & NS & NS & NS & NS & NS \\
\hline Pushpalatha et al. (2011) - India [20] & Overall & 34 & 14 & 2 & 0 & 0 \\
\hline Bindurani et al. (2013) - India [21] & $\begin{array}{l}\text { Overall } \\
\text { Right } \\
\text { Left }\end{array}$ & $\begin{array}{l}28 \\
16 \\
12 \\
\end{array}$ & $\begin{array}{r}18 \\
7 \\
11 \\
\end{array}$ & $\begin{array}{l}4 \\
1 \\
3 \\
\end{array}$ & $\begin{array}{l}0 \\
0 \\
0\end{array}$ & $\begin{array}{l}0 \\
0 \\
0\end{array}$ \\
\hline Yang et al. (2014) - China [22] & Overall & NS & NS & NS & NS & NS \\
\hline Gupta et al. (2015) - India [23] & $\begin{array}{l}\text { Overall } \\
\text { Right } \\
\text { Left }\end{array}$ & $\begin{array}{l}5 \\
4 \\
1 \\
\end{array}$ & $\begin{array}{r}12 \\
9 \\
3 \\
\end{array}$ & $\begin{array}{l}5 \\
3 \\
2 \\
\end{array}$ & $\begin{array}{l}2 \\
2 \\
0\end{array}$ & $\begin{array}{l}0 \\
0 \\
0\end{array}$ \\
\hline Olewnik et al. (2017) - Poland [7] & Overall & 7 & 26 & 10 & 0 & 0 \\
\hline Basanagouda and Halagatti (2017) - India [24] & Overall & 47 & 13 & 2 & 0 & 0 \\
\hline Caetano et al. (2018) - Brazil [8] & Overall & 9 & 21 & 0 & 0 & 0 \\
\hline Gaikwad et al. (2018) - India [25] & $\begin{array}{l}\text { Overall } \\
\text { Right } \\
\text { Left }\end{array}$ & $\begin{array}{l}1 \\
0 \\
1\end{array}$ & $\begin{array}{l}9 \\
3 \\
6\end{array}$ & $\begin{array}{l}21 \\
11 \\
10\end{array}$ & $\begin{array}{l}3 \\
1 \\
2\end{array}$ & $\begin{array}{l}3 \\
2 \\
1\end{array}$ \\
\hline Bertelli et al. (2020) - Brazil [9] & Overall & 0 & 32 & 0 & 0 & 0 \\
\hline Vantmuri and Joshi (2020) - India [26] & $\begin{array}{l}\text { Overall } \\
\text { Right } \\
\text { Left }\end{array}$ & $\begin{array}{r}10 \\
3 \\
7\end{array}$ & $\begin{array}{l}75 \\
40 \\
35\end{array}$ & $\begin{array}{r}15 \\
7 \\
8\end{array}$ & $\begin{array}{l}0 \\
0 \\
0\end{array}$ & $\begin{array}{l}0 \\
0 \\
0\end{array}$ \\
\hline
\end{tabular}

PTM: pronator teres muscle; NS: not specified from their respective studies.

\section{OUTCOMES ON THE NUMBER OF PTM BRANCHES}

Of 648 branches studied from twenty studies have registered $52.9 \%$ of two branch innervation pattern) followed by $31.3 \%$ (for single-branch pattern); $13.5 \%$ (for three- branch pattern); $1.7 \%$ (for four-branch pattern) and $0.4 \%$ (for five-branch pattern), respectively. Pooled data of the branching pattern are listed in Tables 2 and 3 . The percentage of single branches was in the range of $0-53.8 \%$ varying from population to population. The Saudis followed by Turkish population had the lowest single branches. The highest value was found among French population. The two-branch pattern was in the range of $43.6-100 \%$. The Indian followed by Austria and French populations had the lowest double branches while the highest value was found in Saudi population.
In case of three branching pattern, Saudi, Brazilian and British followed by French population had the lowest triple branches. The highest value was found among Turkey and Poland populations. Whereas the percentage of four branching pattern was low in almost all the populations in the range of $0-2.9 \%$. Only one study (25) reported five branches in three specimens ( 2 right and 1 left). 211 branches reported from four studies $(21,23,25$, 26) have analyzed the branching pattern in relation with side and no statistically significant differences $(\mathrm{P}>0.05)$ found between right and left branching patterns. None of the studies have analyzed branching pattern in relation with sex (Table 2). Two studies from USA (10) and China (22) are not included in data as they did not mention the number of branches explicitly as per our search. 
Tab. 3 Showing population wise percentages of the branches to PTM.

\begin{tabular}{|l|c|c|c|c|c|}
\hline \multicolumn{1}{|c|}{ Country } & $\begin{array}{c}\text { \% Single } \\
\text { branches }\end{array}$ & $\begin{array}{c}\text { \% Double } \\
\text { branches }\end{array}$ & $\begin{array}{c}\text { \% Triple } \\
\text { branches }\end{array}$ & $\begin{array}{c}\text { \% Four } \\
\text { branches }\end{array}$ & $\begin{array}{c}\text { \% Five } \\
\text { branches }\end{array}$ \\
\hline $\begin{array}{l}\text { Saudi } \\
\text { Arabia [6] }\end{array}$ & 0 & 100 & 0 & 0 & 0 \\
\hline Turkey [19] & 11.7 & 55.8 & 29.4 & 2.94 & 0 \\
\hline $\begin{array}{l}\text { Brazil } \\
{[8,9,18]}\end{array}$ & 14.5 & 85.4 & 0 & 0 & 0 \\
\hline Poland [7] & 16.2 & 60.4 & 23.2 & 0 & 0 \\
\hline $\begin{array}{l}\text { USA } \\
{[5,10,16]}\end{array}$ & 22.5 & 55 & 20 & 2.5 & 0 \\
\hline Austria [15] & 28 & 44 & 20 & 8 & 0 \\
\hline UK [14] & 33.3 & 66.6 & 0 & 0 & 0 \\
\hline $\begin{array}{l}\text { India [20, } \\
21,23-26]\end{array}$ & 38.6 & 43.6 & 15.1 & 1.54 & 0.9 \\
\hline $\begin{array}{l}\text { France } \\
{[4,17]}\end{array}$ & 53.8 & 44.2 & 1.92 & 0 & 0 \\
\hline
\end{tabular}

PTM: pronator teres muscle.
OUTCOMES ON THE BRANCHING PATTERN OF PTM BRANCHES IN RELATION WITH HIL

Ten of twenty studies comprising 403 PTM branches have reported their location in relation with HIL (Table 4). Of 403 branches studied, majority (203 branches - 50.3\%) located distal to HIL. Whereas 132 out of 403 branches (32.7\%) located proximal to HIL, followed by 68 of 403 branches (16.8\%) at the level of HIL. The French population reported zero percentage of branches located proximal to HIL while Indians having the highest percentage (55.9\%). The American (0\%) followed by French (1.4\%) and Brazilian population (5.8\%) reported the lowest branches at HIL while Indians having the highest (86.7\%). Regarding branches located distal to HIL, it was observed that the British population had low percentage (3.9\%) while the Indian population having the highest (50.2\%) (Table 4). None of the studies have analyzed branching pattern in relation with sex (Table 4). Only one study (23) conducted on 52 branches from Indian population did explicitly analyze distance of the branches from HIL in relation with side and no significant differences $(\mathrm{P}>0.05)$ found between right and left sides (Table 4).

Tab. 4 Outcomes of different studies on anatomical location of the branches with reference to HIL.

\begin{tabular}{|c|c|c|c|c|c|}
\hline \multirow{2}{*}{$\begin{array}{c}\text { Studies (year) } \\
\text { and } \\
\text { Region }\end{array}$} & \multirow{2}{*}{ Type of study } & \multirow{2}{*}{$\begin{array}{l}\text { Gender/ } \\
\text { Side }\end{array}$} & \multicolumn{3}{|c|}{ Number of branches } \\
\hline & & & Proximal to HIL & At HIL & Distal to HIL \\
\hline Sunderland, 1978 - UK [14] & Cadaveric & Overall & 8 & 4 & 8 \\
\hline Canovas et al., 1998 - France [4] & Cadaveric & Overall & 0 & 1 & 9 \\
\hline Tung and Mackinnon, 2001 - USA [5] & Cadaveric & Overall & 7 & 0 & 24 \\
\hline Alves et al., 2004 - Brazil [18] & Cadaveric & Overall & 14 & NR & 7 \\
\hline Safwat and Abdel-Meguid, 2007 - Saudi Arabia [6] & Cadaveric & Overall & 23 & 0 & 23 \\
\hline Gupta et al., 2015 - India [23] & Cadaveric & $\begin{array}{l}\text { Overall } \\
\text { Right } \\
\text { Left }\end{array}$ & $\begin{array}{l}7 \\
4 \\
3\end{array}$ & $\begin{array}{l}27 \\
12 \\
15\end{array}$ & $\begin{array}{r}18 \\
11 \\
7\end{array}$ \\
\hline Basanagouda and Halagatti, 2017 - India [24] & Cadaveric & Overall & 33 & 0 & 29 \\
\hline Caetano et al., 2018 - Brazil [8] & Cadaveric & Overall & 14 & NR & 7 \\
\hline Gaikwad et al., 2018 - India [25] & Cadaveric & Overall & 26 & 32 & 55 \\
\hline Bertelli et al., 2020 - Brazil [9] & Cadaveric & Overall & NR & 4 & 23 \\
\hline
\end{tabular}

HIL: humeral intercondylar line; NR: not reported. 
Fourteen studies that presented population-wise data on the distance of branches located proximal and distal to HIL is shown in Table 5. The branches located proximal and distal to HIL in the range of $1.25-10 \mathrm{~cm}$, and 1.1-7.5 cm, respectively (Fig. 3). None of the studies reported the distances in relation with sex.

Tab. 5 Outcomes on the distance of PTM nerve branches from HIL.

\begin{tabular}{|l|c|c|}
\hline \multicolumn{1}{|c|}{ Studies (year) and Region } & \multicolumn{2}{c|}{$\begin{array}{c}\text { Distance of branches } \\
\text { from HIL (cm) }\end{array}$} \\
\cline { 2 - 3 } & Proximal & Distal \\
\hline Sunderland, 1978 - UK [14] & 7.0 & 2.3 \\
\hline Fuss and Wurzl, 1990 - Austria [15] & 3.5 & 5.5 \\
\hline Gunther et al., 1992 - USA [16] & 4.5 & 3.5 \\
\hline Canovas et al., 1998 - France [4] & 7.1 & 2.4 \\
\hline Tung and Mackinnon, 2001 - USA [5] & 1.25 & 1.35 \\
\hline Alves et al., 2004 - Brazil [18] & 4.9 & 1.5 \\
\hline Bindurani et al., 2013 - India [21] & 1.31 & 1.2 \\
\hline Yang et al., 2014 - China [22] & NR & 3.87 \\
\hline Gupta et al., 2015 - India [23] & 10.0 & 3.0 \\
\hline Olewnik et al., 2017 - Poland [7] & NR & 5.3 \\
\hline Basanagouda and Halagatti, 2017 - & 5.0 & 7.5 \\
\hline India [24] & & \\
\hline Caetano et al., 2018- Brazil [8] & 6.8 & 2.8 \\
\hline Gaikwad et al., 2018 - India [25] & 2.5 & 1.1 \\
\hline Bertelli et al., 2020 - Brazil [9] & 1.5 & 3.8 \\
\hline
\end{tabular}

PTM: pronator teres muscle; HIL: humeral intercondylar line; NR: not reported.

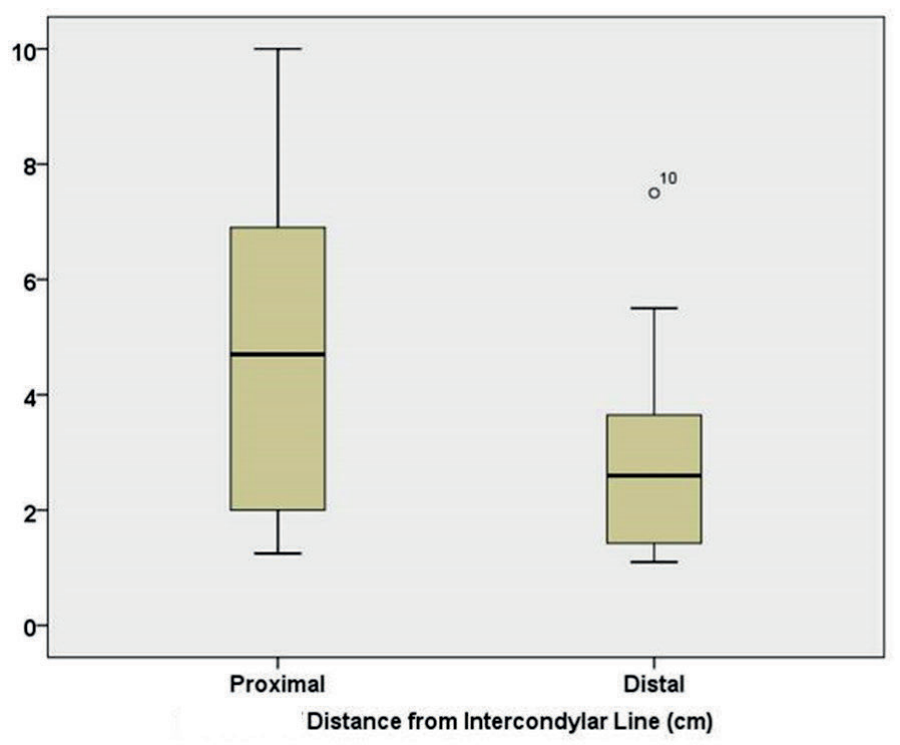

Fig. 3 Showing the distance of PTM branches located proximal and distal to HIL.

HIL: humeral intercondylar line.

\section{OUTCOMES ON THE MEAN LENGTH AND DIAMETER OF PTM BRANCHES}

Six studies $(5,8-10,18,22)$ reported the mean length and three studies (8-10) reported the diameter of PTM branches. The mean length of proximal PTM branches reported from two studies $(5,9)$ was $2.45 \pm 0.25 \mathrm{~cm}$, ranged from $2.2 \pm 0.8 \mathrm{~cm}$ (USA) to $2.7 \pm 8 \mathrm{~cm}$ (Brazil). The mean length of distal branches was $3.35 \pm 0.45 \mathrm{~cm}$, ranged from $2.9 \pm 1.0 \mathrm{~cm}$ (USA) to $3.8 \pm 1.5 \mathrm{~cm}$ (Brazil). Four studies $(8,10,18,22)$ reported the mean length (without specifying the proximal and distal branches) as $5.85 \pm 2.38 \mathrm{~cm}$, ranged from $3.6 \mathrm{~cm}$ (USA) to $9.6 \mathrm{c} \mathrm{m}$ (China). Overall, mean length of the nerves from all reported studies is $4.37 \pm$ $2.43 \mathrm{~cm}$. Only one study from Brazil (9) reported the mean diameter of proximal and distal PTM branches and these were $1.4 \pm 0.4 \mathrm{~mm}$ and $1.3 \pm 0.4 \mathrm{~mm}$, respectively. In two reported studies $(8,10)$ the mean diameter (without specifying the proximal and distal branches) was $1.5 \mathrm{~mm}$. None of the studies analyzed length and diameter of the nerves in relation with sex and side (Table 6).

Tab. 6 Outcomes of different studies on morphometry of the PTM branches.

\begin{tabular}{|c|c|c|c|c|}
\hline $\begin{array}{l}\text { Studies (year) } \\
\text { and Region }\end{array}$ & $\begin{array}{l}\text { Type } \\
\text { of study }\end{array}$ & $\begin{array}{l}\text { Gender/ } \\
\text { Side }\end{array}$ & $\begin{array}{c}\text { Nerve } \\
\text { length }(\mathrm{cm})\end{array}$ & $\begin{array}{c}\text { Nerve } \\
\text { diameter } \\
(\mathrm{mm})\end{array}$ \\
\hline $\begin{array}{l}\text { Tung and } \\
\text { Mackinnon, } \\
2001 \text { - USA [5] }\end{array}$ & Cadaveric & Overall & $\begin{array}{l}2.2 \pm 0.8(P) \\
2.9 \pm 1.0(D)\end{array}$ & NR \\
\hline $\begin{array}{l}\text { Alves et al., } \\
2004 \text { - Brazil } \\
{[18]}\end{array}$ & Cadaveric & Overall & 6.2 & NR \\
\hline $\begin{array}{l}\text { Tubbs et al., } \\
2011 \text { - USA } \\
{[10]}\end{array}$ & Cadaveric & Overall & 3.6 & 1.5 \\
\hline $\begin{array}{l}\text { Yang et al., } \\
2014 \text { - China } \\
{[22]}\end{array}$ & Cadaveric & Overall & $9.64 \pm 0.71$ & NR \\
\hline $\begin{array}{l}\text { Caetano et al., } \\
2018 \text { - Brazil } \\
\text { [8] }\end{array}$ & Cadaveric & Overall & $4.0 \pm 1.2$ & $1.5 \pm 0.6$ \\
\hline $\begin{array}{l}\text { Bertelli et al., } \\
2020 \text { - Brazil } \\
\text { [9] }\end{array}$ & Cadaveric & Overall & $\begin{array}{l}2.7 \pm 8(P) \\
3.8 \pm 15(D)\end{array}$ & $\begin{array}{l}1.4 \pm 0.4(P) ; \\
1.3 \pm 0.4(D)\end{array}$ \\
\hline
\end{tabular}

P: proximal branch; D: distal branch; NR: not reported.

\section{DISCUSSION}

Our study revealed considerable variations in the innervation pattern of PTM contrary to the classic description of anatomical textbooks. We found majority of the branches $(52.9 \%)$ are two in number and most of the branches are located distal to HIL (50.3\%) from the reported studies. Knowledge on the number and location of branches is very important for clinicians in planning the appropriate type of electrostimulation in rehabilitation process to 
restore the motor function $(6,27)$. It is very surprising to see the data on number of PTM branches in relation with gender; side is very vague and quite often not reported in the published studies. The French followed by American population having a low percentage of branches located proximal to HIL. The American followed by French and Brazilian populations having the lowest branches at HIL while Indians having the highest. Whereas the British having low percentage of branches distal to HIL while Indians having the highest (Table 4). We firmly believe that the above comparison and knowledge of knowing their population wise distances from the HIL (Table 5) can be of help while undertaking the surgical intervention procedures associated with pronator teres syndrome, pronator teres rerouting or neurotomy etc.

The quantitative anatomical studies investigating PTM nerve morphometrics are found to be relatively rare. This finding is unexpected given the widespread use of PTM nerves in neurotization procedures. During neurotization procedures, surgeons usually face a challenge in searching an adequate nerve which has an appropriate length and diameter. From our analysis, we found that the length of PTM nerves ranging from $2.2-9.6 \mathrm{~cm}$ (Table 6). Predominantly, studies reported measuring the length of PTM branches from their point of origin (from $\mathrm{Mn})$ to the point where they enter the muscle. Our observation of wide variation in the length of branches is up to $7.4 \mathrm{~cm}$. The nerve length is shown to vary between populations. Our analysis reported the nerve length is shortest in Americans while Chinese having the longest. Despite using the same anatomical landmarks for measurements in both studies, they are seen to have significantly different values (Table 6). The reason for this wide variation could be the differences in usage of embalmed vs. fresh cadavers or the length of limb or age of the cadaveric sample. Our data shows that the branches are in enough length to reach the important motor nerves such as anterior interosseous nerve (AIN), radial nerve branches to extensor carpi radialis brevis (ECRB), extensor carpi radialis longus (ECRL) and posterior interosseous nerve (PIN). Caetano et al. (8) based on findings in 12 limbs reported that one of the PTM branches is too long to be connected to the PIN distal to the emergence of the nerve to supinator muscle.

We analyzed the mean diameter of PTM branches from 82 limbs of three studies (Table 6). The mean diameter of the proximal and distal branches of PTM reported from studies is: $1.45 \pm 0.5 \mathrm{~mm} ; 1.3 \pm 0.4 \mathrm{~mm}$, respectively. Two studies $(8,10)$ on 50 limbs have reported the mean diameter of nerve as $1.5 \mathrm{~mm}$ without specifying the proximal and distal measurements. The reported mean diameter of these nerves is almost compatible and corresponding to the mean diameters of AIN, ECRL and ECRB. Few studies have reported the mean diameter of AIN as $1.6 \mathrm{~mm} \mathrm{(28);} 1.7 \mathrm{~mm}$ (8) and $2.0 \mathrm{~mm}$ (29), respectively. The mean diameter of PTM branches from our analysis is almost corresponding to $94 \% ; 88 \%$ and $75 \%$ of the mean diameter of AIN from the above reported studies. In addition to AIN, the mean diameter of branches for the ECRL $(1.5 \pm 0.6 \mathrm{~mm})$ and ECRB $(1.4 \pm 0.7 \mathrm{~mm})$ reported by Caetano et al. (8) are also corresponding to $100 \%$ and
90\% of the diameter of PTM branches observed by us. On the other hand, studies have also reported the diameter of PIN as $3.0 \pm 0.5 \mathrm{~mm}(8,30)$ and the compatibility of PTM branches to PIN from these reports seems to be $50 \%$. Our analysis on the above compatibilities further supported by a recent histomorphometric study, wherein, the PTM branches are seen to have an average of 646 and 599 myelinated fibers in both proximal and distal branches, respectively. These myelinated fibers are more or less close to the 548 and 457 fibers of ECRB reported $(9,31)$. The above comparison of diameter differences and nerve fibers might give an explicit idea about selecting the donor nerve for neurotization procedures. It may not be possible to get a $100 \%$ accurate donor nerve with identical structure of the recipient nerve at both macro and microarchitectural properties. Few papers published in the past on animal experiments have demonstrated that the axonal multiplication between donor and recipient was $1: 3$ (32) and at least $30 \%$ of the original motor neurons are required to achieve normal muscle function (33). Therefore, the donor nerve must have at least $30 \%$ of the number of axons of the receptor nerve (34). And the quantitative data which we have procured from the literature is clearly supporting the assumption that the PTM branches are compatible (50-100\%) to all the nearby motor nerves.

In conclusion, our pooled data demonstrated that the innervation patterns of PTM branches vary between populations in terms of their number, location, and morphometry. These variations between number, length, diameter, and their placement in relation with HIL could be a result of anatomical dissections they have performed on embalmed vs. fresh cadavers. Although such procedural bias could exist, the larger pooled data of our study could give a standard dataset about their morphometry and we firmly believe that this data is of help for surgeons in comparing donor and recipient sites pre-operatively.

\section{ACKNOWLEDGEMENTS}

Authors would like to thank Dr. Sameer Qureshi, consultant orthopedic surgeon, CHL Medical Center Hospital, Ujjain, India for providing the schematic diagram.

\section{AUTHOR CONTRIBUTIONS}

BKP: Conceptualized and designed the study, reviewed the literature, compiled all the data, drafted the manuscript. MVRS: Independently reviewed the literature, involved in thorough checking of all the data and references. Both authors approved the final manuscript submitted for publication.

\section{COMPETING INTERESTS}

The authors declare that they have no competing interests associated with this manuscript. 


\section{ABBREVIATIONS}

AIN: Anterior Interosseous Nerve ECRB: Extensor Carpi Radialis Brevis, ECRL: Extensor Carpi Radialis Longus

HIL: Humeral Intercondylar Line

Mn: Median nerve

PIN: Posterior Interosseous Nerve

PTM: Pronator Teres Muscle

\section{REFERENCES}

1. Moore KL, Dalley AF, Agur MRA Clinically oriented anatomy. 4th ED. Lippincott Williams and Wilkins, Philadeplphia, 2010.

2. Bergman RA, Miyauchi R, Afifi AK. Illustrated encyclopedia of human anatomic variation: opus I: muscular system: alphabetical listing of muscles, Pronator teres muscle. Anatomy Atlases, The University of Iowa 2015. http://www.anatomyatlases.org/AnatomicVariants/AnatomyHP.shtml

3. Standring S. Gray's Anatomy. 40th Ed. Churchill Livingstone. 2008; p. 781, 828-97.

4. Canovas F, Mouilleron P, Bonnel F. Biometry of the muscular branches of the median nerve to the forearm. Clin Anat 1998; 11(4): 239-45.

5. Tung TH, Mackinnon SE. Flexor digitorum superficialis nerve transfer to restore pronation: two case reports and anatomic study. J Hand Surg Am 2001; 26(6): 1065-72.

6. Safwat MD, Abdel-Meguid EM. Distribution of terminal nerve entry points to the flexor and extensor groups of forearm muscles: an anatomical study. Folia Morphol (Warsz) 2007; 66(2): 83-93.

7. Olewnik, Ł, Podgórski, M, Polguj M, Wysiadecki G, Topol M. Anatomical variations of the pronator teres muscle in a Central European population and its clinical significance. Anat Sci Int 2018; 93: 299-306.

8. Caetano EB, Vieira, LA, Sabongi Neto JJ, et al. Anatomical study of pronator teres muscle innervation and clinical significance in nerve transfer. Int J Morphol 2018; 36(4): 1500-8.

9. Bertelli JA, Nehete S, Winkelmann Duarte EC, Patel N, Ghizoni MF. Distal pronator teres motor branch transfer for wrist extension restoration in radial nerve paralysis. J Neurosurg 2020: 1-7.

10. Tubbs RS, Beckman JM, Loukas M, Shoja MM, Cohen-Gadol AA. Median nerve branches to the pronator teres: cadaveric study with potential use in neurotization procedures to the radial nerve at the elbow. J Neurosurg 2011; 114(1): 253-5.

11. Li Z, Reynolds M, Satteson E, Nazir O, Petit J, Smith BP. Double distal intraneural fascicular nerve transfers for lower brachial plexus injuries. J Hand Surg Am 2016; 41(4): e15-e19.

12. Zhang L, Zhang CL, Cai T, Zhu KP, Hu JP, Dong Z. Comparative study of pronator teres branch transfer and brachialis motor branch transfer to the anterior interosseous nerve to treat lower brachial plexus injury in rats. J Plast Reconstr Aesthet Surg 2020; 73(2): 231-41.

13. Moher D, Liberati A, Tetzlaff J, Altman DG; PRISMA Group. Preferred reporting items for systematic reviews and meta-analyses: the PRISMA statement. PLoS Med 2009; 6(7): e1000097.

14. Sunderland S. Nerves and Nerve Injuries. 2nd ED, Edinburgh; New York: Churchill Livingstone; New York: distributed by Longman, 1978.
15. Fuss F, Wurzl G. Median nerve entrapment. pronator teres syndrome. Surg Radiol Anat 1990; 12: 267-71.

16. Gunther SF, DiPasquale D, Martin R. The internal anatomy of the median nerve in the region of the elbow. J Hand Surg Am 1992; 17(4): 648-56.

17. Chantelot, C, Feugas C, Guillem P, Chapnikoff D, Remy F, Frontaine F. Innervation of the medial epicondylar muscles: an anatomic study in 50 cases. Surg Radiol Anat 1999; 21: 165-8.

18. Nilton A, Laino CP, Renata F. Innervation of the pronator teres muscle. Int J Morphol 2004; 22 (3): 237-40.

19. Demirci SM, Alp M, Marur T, Akkin SM, Yalcin L. Innervation pattern of the pronator teres muscle. Saudi Med J 2007; 28(6): 838-40.

20. Pushpalatha M, Jayanti KS. Variations of number of branches to the pronator teres. Anatomica Karnataka 2011; 5(2): 43-6.

21. Bindurani MK, Lokesh HM, Nanjundappa BN. Study of muscular branch of median nerve to the pronator teres. Natl J Clin Anat 2013; 2(2): 67-70.

22. Yang J, Jia X, Yu C, Gu Y. Pronator teres branch transfer to the anterior interosseous nerve for treating C8T1 brachial plexus avulsion: an anatomic study and case report.Neurosurgery 2014; 75(4):375-9.

23. Gupta C, Seva KN, Kalthur SG, D'souza AS. A morphometric study of variations in the innervation of pronator teres with its clinical implications. J Med Sci 2015; 35(3): 97-9.

24. Basanagouda C, Halagatti M. Innervation pattern of pronator teres muscle and its relation to median nerve: a cadaveric study. Int J Anat Res 2017; 5(3.1): 4092-95.

25. Gaikwad AP, Pandhare SR, Paranjape V. Surgical anatomy of median nerve in relation to pronator teres muscle: a cadaveric study. Appl Physiol Anat Digest 2018; 2(4): 52-61.

26. Vantmuri HS, Joshi UU. Innervations of pronator teres muscle by median nerve: a cadaveric study. Int J Anat Res 2020; 8(2.2): 7470-5.

27. Wu L, Goto Y, Taniwaki T, Kinukawa N, Tobimatsu S. Different patterns of excitation and inhibition of the small hand and forearm muscles from magnetic brain stimulation in humans. Clin Neurophysiol 2002; 113(8): 1286-94.

28. Tubbs RS, Custis JW, Salter EG, et al. Quantitation of and superficial surgical landmarks for the anterior interosseous nerve. J Neurosurg 2006; 104(5): 787-91.

29. Matavelli FC, Gobbi L, Dos Santos MPS, Caetano EB, Vieria LA, de Andrade RA. Transfer of the radial nerve branches for the treatment of the anterior interosseous nerve lesion: an anatomical study. Acta Ortop Bras 2019; 27(6): 298-303.

30. Caetano EB, Vieira LÂ, Sprovieri FA, Petta GC, Nakasone MT, Serafim BL. Anatomical variations of pronator teres muscle: predispositional role for nerve entrapment. Rev Bras Ortop 2017; 52 (2): 169-75.

31. Sukegawa K, Suzuki T, Ogawa Y, Kobayashi T, Matsuura Y, Kuniyoshi K. A cadaver study of median-to-radial nerve transfer for radial nerve injuries. J Hand Surg Am 2016; 41: 20-6.

32. Lutz BS, Chuang DC, Chuang SS, Hsu JC, Ma SF, Wei FC. Nerve transfer to the median nerve using parts of the ulnar and radial nerves in the rabbit - effects on motor recovery of the median nerve and donor nerve morbidity. J Hand Surg Br 2000; 25(4): 329-35.

33. Tötösy de Zepetnek JE, Zung HV, Erdebil S, Gordon T. Innervation ratio is an important determinant of force in normal and reinnervated rat tibialis anterior muscles. J Neurophysiol 1992; 67(5): 1385-403.

34. Jiang BG, Yin XF, Zhang DY, Fu ZG, Zhang HB. Maximum number of collaterals developed by one axon during peripheral nerve regeneration and the influence of that number on reinnervation effects. Eur Neurol 2007; 58(1): 12-20. 